silver. On first sounding I only obtained negative results, but afterwards distinct evidence of calculus. Drs. Leahy and Tweed, of this place, afterwards examined the patient with me, when we all distinctly felt something in the bladder, more like a hard ridge than anything else, whilst we failed to obtain characteristic evidence of calculus Nevertheless, as we were certain there was something in the bladder, and his pain and other symptoms were severe, an operation was decided upon, and $I$ chose the supra-pubic, because, having just previously extracted a very large calculus by that operation, I had learnt the great command it gave over the bladder-an important point when, as in this case, I was uncertain respecting its contents.

On Nov. 18th, the patient having been placed under chloroform, I operated in the usual manner, and at the bottom of the bladder found a number of calculi of various sizes, and, on turning my finger round, a stick-like substance coiled upon itself, hard and rigid, which, on attempting to remove, appeared to be rather firmly attached to the surface of the bladder, and proved to be a small French catheter, to which was attached a considerable quantity of phosphatic calculus, much of which fell back into the bladder during withdrawal, and was afterwards removed by the scoop and irrigation. The after history of the case was uneventful. He passed all his urine per urethram on the tenth day, and the external wound is now (Dec. 30th) nearly healed. He is free from pain, in good health, and urine normal. I received valuable assistance in this case from Drs. Tweed and Leahy.

The mystery of the catheter is, I think, easily solved. My patient is not a total abstainer ; in fact, he freely confessed that he often drank "not wisely, but too well." In July last, when suffering from influenza, he came in from the country to one of the hotels, went to bed with some hot grog, most likely used the catheter, left it in and went to sleep, and, forgetting all about it, it became drawn into the bladder. At any rate, the pains dated from that night, and the passing of gravel a short time after.

Ashburton, Canterbury, N.Z.

\section{A CASE SIMULATING PEMPHIGUS.}

By Arthur J. Moss, M.B., Ch.B., \&c.

THE case recorded by Mr. Clarke in THE LANcet of Jan. 4th last leads ne to describe a case which occurred recently in my own practice.

I was sent for hurriedly late on the night of Dec. $27 \mathrm{th}$ last to see a boy aged nine who had been ill all day. The previous day he had been quite well. On arrival I found him restless, and suffering from slight cough, pains in the legs, and bad headache. The temperature was $100 \cdot 2^{\circ}$. On examination of the legs $I$ found over the anterior tibial region of both an irregular reddened patch some four inches long, on which were scattered numerous small vesicles about the size of a pea. The general appearance of the patches looked exactly like herpes, if such a thing as symmetrical herpes were possible. The bowels being loaded and the tongue foul, I simply ordered a purgative. The mother informed me that she was quite sure the eruption was not present in the morning. At my next visit the boy felt much better; headache and cough had disappeared, and the bowels acted freely. The eruption on the legs had altered in character, the reddened base had faded, but the vesicles had run together to form large bullæ, some of them of the size of walnuts, tensely filled with a clear serous fiuid. I now prescribed a little arsenic, and ordered the eruption to be dusted with zinc oxide. In a few days the boy was quite well in general health; the large bullæ collapsed from reabsorption of their contents, and disappeared, leaving a slightly reddened surface to mark their position.

I subsequently found out that the boy on the day of my first visit had been sitting close to the fire all day, and had most probably scorched his legs. But if this be the correct explanation of the eruption, is it usual for the blisters caused by heat to increase so enormously in size after removal of the cause? At first the case was very puzzling on account of the raised temperature, cough, and headache coincident with the eruption. There has been no recurrence of the eruption, and at the present time the patient is perfectly well.

Penarth, Glamorgan.

\section{ALBUMINOUS URINE INDEPENDENT OF} KIDNEY DISEASE.

By Henry Lee,

CONSULTING SURGEON TO ST. GEORGE'S HOSPITAL.

CASE 1.-An eminent engineer when comparatively young met with a serious accident. Many years afterwards it was found that his urine was albuminous. A consultation took place between Sir B. Brodie, Dr. Owen Rees, Dr. Seth Thompson, and myself. The general opinion was that the best chance of prolonging his life was to send him to Egypt. I ventured to remind Sir B. Brodie that when I was his clinical clerk at St. George's Hospital notes had been taken of cases of albuminous urine in which no disease of the kidneys was found after death. The patient went to Egypt After his return he engaged in a most arduous undertaking, which taxed his energies to the uttermost. This at last he accomplished, but within a very few days he was seized with an attack of apoplexy, of which he very shortly died. Dr. Seth Thomspon, Mr. Charles Hawkins, and myself were present at the post-mortem examination. The kidneys were small, but not diseased. There was an intussusception of the right ureter. The invaginated portion was as large as a walnut and as red as the reddest cherry. This intussusception was subsequently supposed to have occurred at the time of the accident above referred to. The source of the albumen in the urine was now no longer doubtful.

CASE 2.-A gentleman who had had syphilis was under the care of the late Dr. Cumberbatch and myself. He had suppurating caries of one of his ribs; the urine was highly albuminous. Under a mild but sustained course of calomel baths, with a pint of the simple decoction of sarsaparilla daily, he completely recovered; the albumen entirely disappeared from his urine, and he got married.

CASE 3.-A gentleman contracted syphilis early in life. From this he was apparently cured. Later on he had a second attack, and for this the treatment was not properly carried out. For some years he had occasional eruptions of pimples on different parts of the borly. For these he took mercury irregularly both in England and abroad. At length he appeared to have been quite cured. Last year he came home from abroad in a great state of alarm, saying that a medical man had sent him home on account of his urine being albuminous. The urine was frequently tested with heat and acid, and there was always a thick white deposit extending half-way up the fluid in the test-tube. The patient seemed much depressed, and had lost considerably in weight. He was ordered nitro-hydrochloric acid and iron. To my great surprise I found after some time that there was no longer any albumen in the urine. I subsequently learnt that this patient had had a most severe family affliction, involving a lawsuit, which had been satisfactorily settled. After the settlement of the lawsuit there was no more albumen in the urine.

Savile-row, $w$.

CENTRAL RUPTURE OF PERINEUM.

BY A. E. WELLS, M.D. LOND.

Mrs. T_- a strong, healthy woman, aged twenty-four, was confined of her first child on Feb. 12th, at about the end of the eighth month. Labour was rapid till the hesd reached the perineum and the occiput presented at the vulva. The pains then lessened, and no progress was made for three hours, although the perineum appeared soft and easily dilatable. I then gave a drachm of liquid extract of ergot and in twenty minutes moderate pains began and completed the birth in another half hour. On examination, there was found to be a tear of the perineum extending from midway hetween the anus and fourchette forwards and to the left, just superficially notching the left labium a quarter of an inch in front of the fourchette. At its posterior extremity the tear penetrated into the vagina, there being a hole just admitting the forefinger; but anteriorly the laceration was crossed by a band consisting of the lower part of the posterior vaginal wall and some perineal tissue. Behind and above this was a second very slender band crossing the tear from side to side, and consisting apparently only of mucous membrane. The fourchette was not torn, and the only injury to the vulva was a slight superficial notch on the left labium. No sutures were used, and by the fourth day the laceration was quite healed and the patient subsequently did well.

Cuckfield, Sussex. 